Article

\title{
Agricultural Water Use Sustainability Assessment in the Tarim River Basin under Climatic Risks
}

\author{
Jun Zhang ${ }^{1,2}$, Minghao Bai ${ }^{1,3, *}$, Shenbei Zhou ${ }^{1,3,4}$ and Min Zhao ${ }^{1,3}$ \\ 1 Business School, Hohai University, Nanjing 211100, China; zhang_jun@ctgsail.com (J.Z.); \\ zsb@hhu.ed.cn (S.Z.); zhaomin3451@sina.com (M.Z.) \\ 2 China Three Gorges International Corporation, Islamabad 44000, Pakistan \\ 3 Water Resources Economics Research Institute, Hohai University, Nanjing 211100, China \\ 4 Department of Management and Economics, Tianjin University, Tianjin 300072, China \\ * Correspondence: mybai2@hhu.edu.cn
}

Received: 1 December 2017; Accepted: 6 February 2018; Published: 8 February 2018

\begin{abstract}
Proper agricultural water management in arid regions is the key to tackling climatic risks. However, an effective assessment of the current response to climate change in agricultural water use is the precondition for a group adaptation strategy. The paper, taking the Tarim River basin (TRB) as an example, aims to examine the agricultural water use sustainability of water resource increase caused by climatic variability. In order to describe the response result, groundwater change has been estimated based on the Gravity Recovery and Climate Experiment (GRACE) and the Global Land Data Assimilation System (GLDAS)-Noah land surface model (NOAH) data. In order to better understand the relationship between water resource increase and agricultural water consumption, an agricultural water stress index has been established. Agricultural water stress has been in a severe state during the whole period, although it alleviated somewhat in the mid-late period. This paper illustrates that an increase in water supply could not satisfy agricultural production expansion. Thus, seasonal groundwater loss and a regional water shortage occurred. Particularly in 2008 and 2009, the sharp shortage of water supply in the Tarim River basin directly led to a serious groundwater drop by nearly $20 \mathrm{~mm}$ from the end of 2009 to early 2010. At the same time, a regional water shortage led to water scarcity for the whole basin, because the water consumption, which was mainly distributed around Source Rivers, resulted in break-off discharge in the mainstream. Therefore, current agricultural development in the Tarim River basin is unsustainable in the context of water supply under climatic risks. Under the control of irrigation, spatial and temporal water allocation optimization is the key to the sustainable management of the basin.
\end{abstract}

Keywords: Tarim River basin; climatic risks; agricultural water consumption; groundwater change

\section{Introduction}

The largest amount of water is consumed by agricultural production, accounting for at least $80 \%$ of global water withdraws [1]. However, water scarcity has gradually evolved into a global systemic crisis [2,3]. That poses a great challenge to global food production security [4]. Due to population growth, increasing food production demand will aggravate the crisis of water scarcity [5]. Agricultural water use sustainability is an urgent issue, especially in arid and semiarid basins. Worse yet, climatic variability poses the risk of uncertainty for that issue. Considering the uncertainty of climatic variability to the sustainable development of river basins, it should take into consideration the human activity response on climatic risks when it comes to the study of the sustainability of river basins. To different basins, climatic risks impacts are not the same, and could be more humid or arid [6]. Often, research studies on climatic risks focus on how to manage agricultural water use in order to achieve a new balance in a more arid climate, such as Alauddin and Sarker [7], Adamson et al. [8], and Heinemann et al. [9]. 
Under the circumstances, we just passively adapt to climatic risks, and can only take a few high-cost strategies, such as large-scale water efficiency improvement, water transfer, and population migration. However, the climate, which is more humid in some basins with water resource system vulnerability, provides another scenario. In the context of increasing water resources, will these regions respond with initiatives to that change with a long-term interest in sustainable development, or will they encourage agricultural expansion for short-term benefits? In spite of increasing water resources, an improper response may still cause social and ecological security issues in basins, thus posing a serious threat to the region's sustainable development. So, this issue is also worth our attention. Their responses will provide experiences or lessons to adapt to climatic risks while regions are in a relatively favorable position. To better understand their responses, a reliable assessment is needed, which would provide us with detailed evidence.

Groundwater, as an important freshwater storage, has a great contribution to ecosystem sustainability [10,11]. It also plays a more critical role than surface water in enhancing human adaptions to hydroclimatic variability caused by climatic variability $[10,12]$. Especially in arid and semiarid regions, groundwater is heavily relied on for irrigation, industrial production, and people's lives $[13,14]$. However, overabstraction is growing to become a greater challenge for many regions in the world [15]. It can cause a series of severe environmental crises, such as water pollution, salinization, land subsidence, and water table falling [16]. Therefore, groundwater change (GWC) is taken as a sustainability index to reflect agricultural water use adaption to climatic risks in the paper.

Groundwater, as a non-excludable but subtractable common-pool resource, is difficult to be assessed and monitored [14]. It is not possible to obtain full information on this invisible resource, such as the physical structure of the resource and other users' exploitation. In order for users and managers to form effective and unified management strategies [17,18], full information is needed to undertake the expensive and difficult task of groundwater monitoring [19]. However, developing countries and regions often don't have the capacity to do that [19]. Traditional agricultural water use data also doesn't provide sufficient spatial-temporal information to support management decisions of agricultural water use under climatic risks. In the past, regional or national public statistic data, as a single value, was the only reliable resource to estimate water use [20]. However, water use is not a static variable; the statistical data at a larger level is unable to reflect local information about water use stress [20]. Moreover, the data is often from annual statistics, and cannot represent seasonal changes in water use.

Hydrological remote sensing data provides a solution to problems of groundwater monitoring and spatial-temporal agricultural water use information. The launch of the Gravity Recovery and Climate Experiment (GRACE) has detected spatial-temporal variations of terrestrial water storage (TWS), after removing atmospheric and oceanic effects [21]. TWS, which is defined as all forms of groundwater and surface water storage, plays a fundamental role within regional climate and water resources management, especially in arid regions [22,23]. Further assessment of GWC requires a combination of ground-based observational data. The Global Land Data Assimilation System (GLDAS) integrates satellite and ground-based observational data products to simulate water storage components [24]. Based on the combination of GRACE and GLDAS, GWC can be estimated, such as Henry et al. [25], Ouma et al. [26], Huo et al. [27], Xiao et al. [28], and Hu et al. [29].

GWC is determined by the difference in the average rate of replenishment and consumption [10]. Regardless of the consumption, a more humid climate brings more water, which indicates that more water is added to groundwater. Nevertheless, the large-scale agricultural water use constitutes a major modification to the water budget in the arid basin [30]. Perry pointed out that water that is used after agricultural consumption in a river basin is no longer available for others due to evaporation [31]. Furthermore, in the process of large-scale irrigation, phreatic evaporation can also cause a non-productive loss of water [32]. However, evaporation is not the only way to cause water loss. Blue water, referring to irrigation, and green water, from precipitation that is stored in the root zone of the soil and incorporated into harvest crops, are also transferred from local water 
resources [33]. So, agricultural water consumption (AWC) is multifaceted. In short, large amount of water are consumed by agricultural production in different ways. Thus, based on the water budget balance, AWC can be estimated after removing factors of natural water storage changes.

The paper, taking the Tarim River basin as an example, assesses agricultural water use sustainability in the context of an increasing water supply (WS) led by climatic variability, from the evidence of GWC. Then, based on AWC and WS, which included river water and precipitation, an agricultural water stress index is established to describe regional water scarcity in the process of agricultural production, followed by GRACE and the Noah land surface model within the GLDAS (GLDAS-NOAH) data to estimate groundwater change. Based on their spatial and temporal changing patterns, the sustainability of agricultural development in TRB will be analyzed.

\section{Study Area}

The Tarim River basin presents itself as a concise prototype objective. As an arid inland basin, its water mainly is sourced from inland rivers formed by mountain snowmelt and precipitation. There are barely any human activities to water environment runoff before reaching the mountain exit, and no water addition to a runoff, because the basin stays in the condition of poor precipitation and strong evaporation. Thus, it can be concluded that the water after mountain exit is affected by human activity, and mainly agricultural production.

The TRB is the largest inland basin in China, covering an area of 1.04 million $\mathrm{km}^{2}\left(34^{\circ} 55^{\prime}-43^{\circ} 08^{\prime} \mathrm{N}\right.$, $73^{\circ} 10^{\prime}-94^{\circ} 05^{\prime}$ E) (Figure 1). It is surrounded by mountains: the Tian Shan in the north, Kunlun in the south, and Pamir in the west. Due to the poor precipitation and strong evapotranspiration, the extremely arid basin mainly relies on river water from snowmelt in the mountains to support human activities and natural ecosystems [34]. In the TRB, there are four major headstreams: the Akesu River, the Hotan River, the Yarkand River, and the Kaidu-Kongqi River. There is also one mainstream (the Tarim River) [35]. These rivers are lifelines for the survival of agricultural oases.

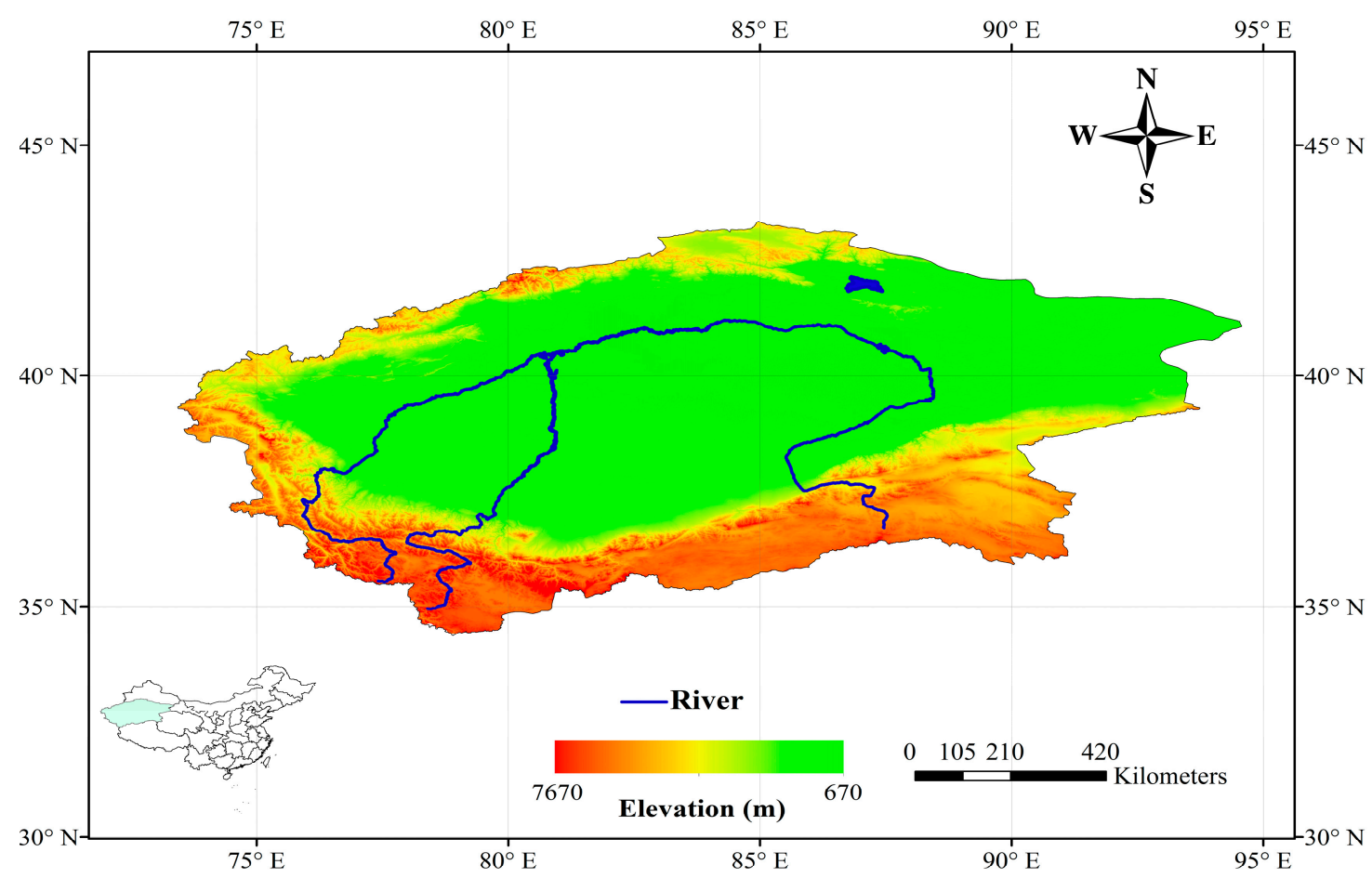

Figure 1. The schematic topography map of the study area.

Agriculture is the most important economic activity in the TRB, and irrigation water is in great demand. So, under the condition of limited water resources, competition for water use between 
agricultural production and natural ecosystems is inevitable [34]. Since the 1960s, the TRB has experienced a continuous expansion of modern oasis agriculture [23]. Especially over last two decades, total agricultural land use has more than doubled [34]. In the process of such sharp expansion, cotton, which has become a major crop, has been shifted from small-scale to large-scale intensive farming [34]. In short, agricultural expansion has had a significant impact on the basin through water scarcity.

Glacier melting and precipitation in the mountains play key roles in water system and hydrological processes [36]. A significant increase in precipitation and temperature has been found in the TRB [37]. Tao et al. concluded that its annual mean precipitation, temperature, and relative humidity have shown positive trends since 1961 [38]. Huang et al. predicted in the period of 2016-2035 that the minimum temperature and annual total precipitation on wet days would show a trend of growth in the most of the TRB [39]. Glacier changes, as the signal of climatic variability, represent an indirect and delayed consequence [40]. However, glacier mass loss has been proven by some studies, such as Shangguan et al. [41], Osmonov et al. [42], and Tino Pieczonka and Tobias Bolch [43]. Consequently, under the multiple influences of climatic risks, ubiquitous warming, increasing precipitation, and retreating glaciers, seasonal river discharges show an increasing trend [44].

Based on above, WS has increased for decades under climatic variability, and would continue for a two-decade period. In the context of climatic variability, the increase in WS is also accompanied by an increase in agricultural water consumption. What's more, the accompanying relationship can be regarded as a response from local agricultural development to the climatic risks. GWC provides an answer to the sustainability of this response. However, due to lack of TWS data from GRACE, which was collected from 2002, we only selected a part of the whole climatic variability period (from 2002 to 2016) to examine. Besides, evidence of climatic variability in the TRB has been proven by previous studies. So, they are not repeated in the paper. We only focus on the relationship between WS, AWC, and GWC under climatic risks.

\section{Methods and Data}

\subsection{Methods}

Glaciers in the TRB can be regarded as large reservoirs that provide fresh water for the downstream by glaciers melting. Meanwhile, streamflow from the headwaters also considers other natural factors such as precipitation, evaporation, and infiltration. So, the streamflow is described as Equation (1):

$$
\mathrm{RF}_{G}=\mathrm{GM}_{G}+\mathrm{P}_{G}-\mathrm{E}_{G}-\mathrm{T}
$$

where $\mathrm{RF}_{G}$ is the streamflow of the headwater before it exits the mountains, $\mathrm{GM}_{G}$ is the glacier's melt, $\mathrm{P}_{G}$ and $\mathrm{E}_{G}$ represent precipitation and evaporation in the glaciers, respectively, and $\mathrm{T}$ refers to the threshold value, which mainly includes two parts: infiltration and freeze. So, when the snowmelt and precipitation rates exceed the infiltration and freezing rates, runoff will be formed.

For any area in the TRB, all of the economic activities, especially agriculture and urban life, as well as the natural ecosystems, are very dependent on the river water as a major water source [34]. However, as an arid region, agricultural production is also inseparable from water supply and precipitation. Xinchun et al. [1] has proven that green water contributes a significant part of agricultural production water use. So, the available water supply (WS) in area $i$ can be given by Equation (2):

$$
\mathrm{WS}_{i}=\mathrm{RF}_{i}+\mathrm{P}_{i}-\mathrm{E}_{i, n a}
$$

where $\mathrm{RF}_{i}$ is the runoff from the headwater to the area $i$ located at the foot of the mountains, which is the difference between inflows and outflows; $\mathrm{RF}_{G}=\sum \mathrm{RF}_{i}+\mathrm{L}, i=1,2, \ldots, n$; $\mathrm{L}$ represents the loss of runoff in the process of flow; $\mathrm{P}_{i}$ and $\mathrm{E}_{i, n a}$ are precipitation and natural evaporation in the area $i$, respectively, and natural evaporation is represented by direct evaporation from bare soil in the paper. 
Meanwhile, water demand can be divided into two parts: human activities water uses and TWS. In terms of water uses, agricultural water use occupies an absolute large share in the TRB. In the agricultural production process, in addition to evaporation, the other part of water consumption (in the form of embedded water) is transferred out. As for TWS, it is a vertical integration of surface water, soil moisture, groundwater, and plant canopy surface water [45]. Crops water content is also included in the plant canopy surface water. However, compared with rapidly expanding agriculture, the other biomass is much steadier. So, without considering crops, the change of plant canopy surface water may be ignored. Based on the above, a water-balance approach on a monthly time step is used as follows:

$$
\Delta \mathrm{TWS}_{i}+\mathrm{AWC}_{i}=\mathrm{RF}_{i}+\mathrm{P}_{i}-\mathrm{E}_{i}
$$

And:

$$
\Delta \mathrm{TWS}_{i}=\Delta \mathrm{SM}_{i}+\Delta \mathrm{GW}_{i}+\Delta \mathrm{SWE}_{i}
$$

As for agricultural water consumption (AWC):

$$
\mathrm{AWC}_{i}=\Delta \mathrm{PCW}_{i}+\mathrm{CE}_{i}+\mathrm{TP}_{i}
$$

where $\Delta \mathrm{TWS}_{i}$ is the change of terrestrial water storage; $\Delta \mathrm{SM}_{i}, \Delta \mathrm{GW}_{i}$ and $\Delta \mathrm{SWE}_{i}$ refer to changes in soil moisture storage, groundwater, and snow water equivalent, respectively; $\mathrm{AWC}_{i}$ is water consumption by crops; and $\triangle \mathrm{PCW}_{i}, \mathrm{CE}_{i}$, and $\mathrm{TP}_{i}$ refer to the plant canopy water change, canopy water evaporation, and transpiration in the crop fields, respectively.

Then, groundwater changes (GWC) can be estimated as follows:

$$
\Delta \mathrm{GW}_{i}=\mathrm{RF}_{i}+\mathrm{P}_{i}-\mathrm{E}_{i}-\mathrm{AWC}_{i}-\Delta \mathrm{SM}_{i}-\Delta \mathrm{SWE}_{i}
$$

For better understanding GWC caused by AWC and WS, the agricultural water stress index (AWSI) first proposed by Xinchun et al. [1] is introduced. However, our index is different from the one proposed by Xinchun et al. [1] in that groundwater is not included in the index, because groundwater is the target of investigation rather than an intermediate variable in this paper. The calculation is shown in Equation (7):

$$
\mathrm{AWSI}_{i}=\frac{\mathrm{AWC}_{i}}{\mathrm{RF}_{i}+\mathrm{P}_{i}-\mathrm{E}_{i}}
$$

And AWSI is categorized into five gradations as defined by Raskin et al.: no water stress $(<0.1)$, low-water stress $(0.1-0.2)$, mid-water stress $(0.2-0.4)$, high water stress $(0.4-0.8)$, and severe water stress $(>0.8)[46]$.

\subsection{Data}

The total water storage of Gravity Recovery and Climate Experiment (GRACE) land data to study the changes in TWS was obtained from http:/ / grace.jpl.nasa.gov, supported by the Making Earth System Data Records for Use in Research Environments Program of National Aeronautics and Space Administration (NASA MEaSUREs Program), with a spatial sampling of $1^{\circ} \times 1^{\circ}$, and a temporal sampling of 30 days for the period of 2002-2016 for the TRB [47]. Monthly gravity solutions in the official GRACE Science Data System are continuously released from three different processing centers: GFZ (Geoforschungs Zentrum, Potsdam, Germany), CSR (Center for Space Research at University of Texas, Austin, TX, USA), and JPL (Jet Propulsion Laboratory, Pasadena, CA, USA). Solutions from JPL, CSR, and GFZ were combined by averaging to compute the TWS in the study. In the process of computing, the land grid scaling applied the same filters that were applied to the GRACE data to a numerical land-hydrology model, such as a NOAH land model, running within the Global Land Data Assimilation System (GLDAS-NOAH), and the error estimation for the scaled values were also considered [21,48]. Due to 'battery management' or instrument issues, several months' data are 
missing in the solutions from all three centers. The corresponding months to the missing data are ignored in the study, as shown in Table 1.

Table 1. The corresponding time to the missing data from January 2002 to December 2016.

\begin{tabular}{|c|c|c|c|c|c|c|c|c|c|c|c|c|}
\hline \multirow{2}{*}{$\begin{array}{l}\text { Time } \\
\text { Year }\end{array}$} & \multicolumn{12}{|c|}{ Months } \\
\hline & 1 & 2 & 3 & 4 & 5 & 6 & 7 & 8 & 9 & 10 & 11 & 12 \\
\hline 2002 & $\mathrm{Na}$ & $\mathrm{Na}$ & $\mathrm{Na}$ & & & $\mathrm{Na}$ & $\mathrm{Na}$ & & & & & \\
\hline 2003 & & & & & & $\mathrm{Na}$ & & & & & & \\
\hline 2004 & & & & & & & & & & & & \\
\hline 2005 & & & & & & & & & & & & \\
\hline 2006 & & & & & & & & & & & & \\
\hline 2007 & & & & & & & & & & & & \\
\hline 2008 & & & & & & & & & & & & \\
\hline 2009 & & & & & & & & & & & & \\
\hline 2010 & & & & & & & & & & & & \\
\hline 2011 & $\mathrm{Na}$ & & & & & $\mathrm{Na}$ & & & & & & \\
\hline 2012 & & & & & $\mathrm{Na}$ & & & & & $\mathrm{Na}$ & & \\
\hline 2013 & & & $\mathrm{Na}$ & & & & & $\mathrm{Na}$ & $\mathrm{Na}$ & & & \\
\hline 2014 & & $\mathrm{Na}$ & & & & & $\mathrm{Na}$ & & & & & $\mathrm{Na}$ \\
\hline 2015 & & & & & & $\mathrm{Na}$ & & & & $\mathrm{Na}$ & $\mathrm{Na}$ & \\
\hline 2016 & & & & $\mathrm{Na}$ & & & & & $\mathrm{Na}$ & $\mathrm{Na}$ & & \\
\hline
\end{tabular}

Using advanced land surface modeling and data assimilation techniques, GLDAS integrates satellite and ground-based observational data products to reveal optimal fields of land surface states and fluxes [37]. Precipitation (snow and rain), runoff (storm surface runoff and baseflow-groundwater), snowmelt, soil moisture, snow depth water equivalent, canopy water evaporation, transpiration, direct evaporation from bare soil, and plant canopy surface water provided by GLDAS-NOAH Version 2.1, with a combination of model and observation-based forcing datasets [49]. So, all of the data were obtained from https: / / disc.sci.gsfc.nasa.gov / datasets?keywords=GLDAS, with a spatial resolution at $1^{\circ} \times 1^{\circ}$ grids

\section{Results and Discussion}

\subsection{Agriculture Water Stress Index}

Figure 2 shows seasonal average spatial patterns of the AWSI and the change trend of the AWSI at the $1^{\circ} \times 1^{\circ}$ grid over the region in the period of 2002-2016. As shown in Figure 2a-c, the large-scale agricultural production was almost distributed around three Source Rivers: the Akesu River, the Hotan River, and the Yarkand River; and the upper mainstream of the Tarim River. The result is confirmed by Wang et al. [50], who have pointed out that water consumption from runoff by the midstream and downstream of the Tarim River was less than 3\% of the upstream part, including the three source rivers, in 2008. Compared with the midstream and downstream, a large amount of water supply from rivers was also accompanied by a large amount of AWC, resulting in high AWSI. This result may indicate groundwater losses in the part of the TRB.

As shown in Figure 2a, nearly half of the areas where large-scale agricultural production is located had been under severe long-term agriculture water stress in the spring of the period. While in the summer, the situation had become even more severe. Almost all of the areas had been under very severe long-term agriculture water stress, as shown in in Figure $2 b$. Two is the maximum value of the AWSI set by the paper. The terrible result represents the seasonal rainfall, and river water was not enough to meet the demand for agricultural production in the summer. In the autumn, the water stress had been somewhat relieved, but could not fundamentally reverse the situation of severe agriculture water stress, because the AWC in most areas still exceeded WS, especially at the edge (Figure 2c). However, in the view of time series, it was found that the frequency of the severe agriculture water 
stress occurrences is gradually reducing, as shown in Figure $2 \mathrm{~d}$. In the early part of the period, nearly half or more of the months in each agricultural life cycle were under severe water stress, especially in 2004, 2008, and 2009. While in 2015 and 2016, the index of only two months each year exceeded 0.8. Most of the time, they were under moderate or high-water stress. To better describe the temporal change in water stress, the trend of annual average is shown in Figure 3.
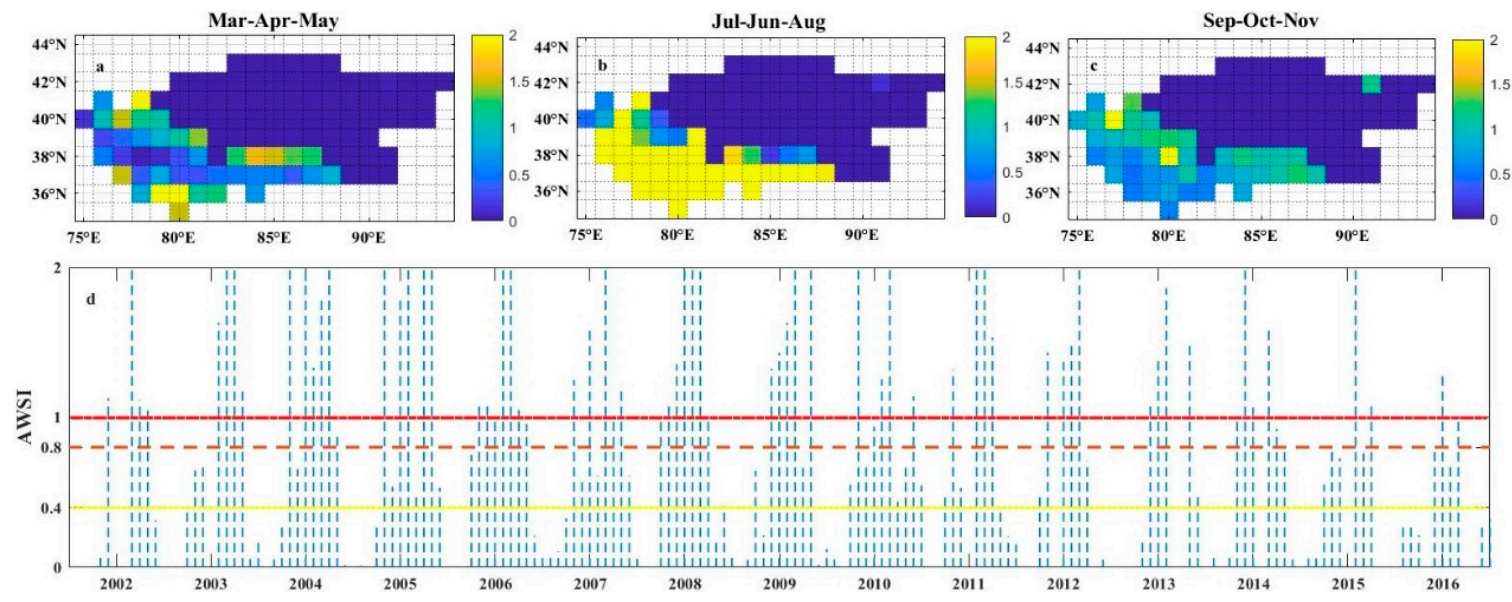

Figure 2. The spatial and temporal pattern of the agricultural water stress index (AWSI) over the region between 2002 and 2016. ((a-c) are spring, summer, and autumn AWSI patterns, respectively; (d) is the monthly average change trend of AWSI).

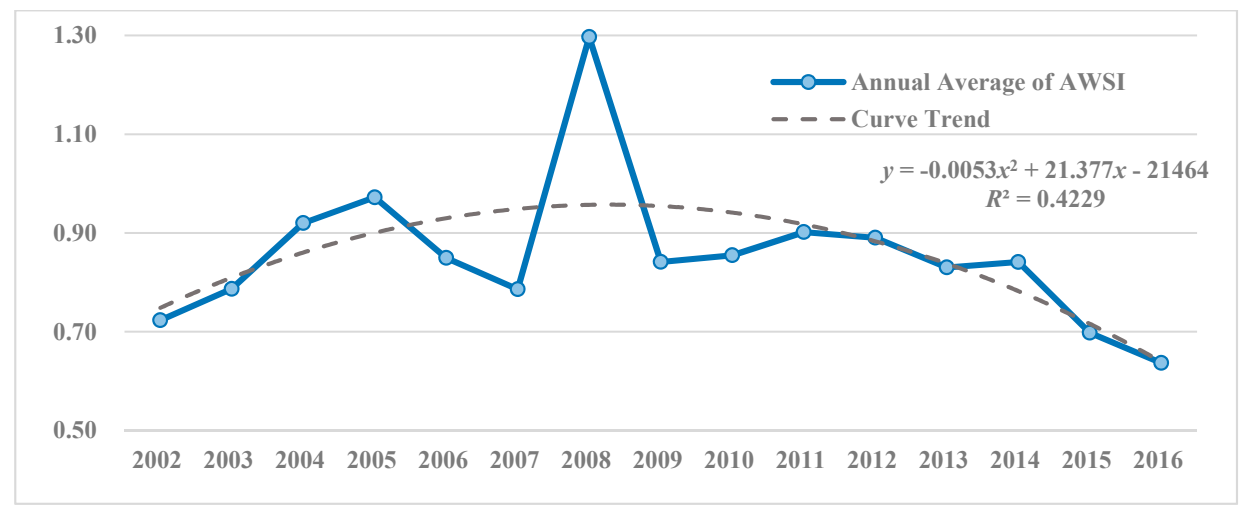

Figure 3. The annual average trend of AWSI and its quadratic fitting during 2002-2016.

Figure 3 shows the trend of the annual average of AWSI and its curve fitting in the period between 2002 and 2016. The annual average value in the TRB shows a trend of increasing first, and then decreasing, culminating in 2008 (1.30). After 2011, it decreases all the way down to the minimum (0.64) in 2016, but it is still much higher than the upper limit of mid-water stress. From the whole period, the TRB has always been in the state of severe water stress, but its stress has been lightening in the mid-late period.

Based on these results, large-scale agricultural production may cause two serious problems in the TRB. One is that downstream of the Tarim river appeared to be cut off, because a large amount of AWC in the upstream led to the lack of runoff, as Wang et al. [50], Chen et al. [51], and Hao et al. [52] mentioned. The other one is seasonal water shortage. Considering river water and rainfall as the major agricultural water sources, both could not meet the demand of AWC in summer and autumn, which led to ecological water shortage and groundwater loss. Also, domestic and other economic activities' water use was difficult because of the water shortage. However, judging by the declining trend of 
AWSI, the problem of excessive AWC was being solved step by step. Increasing irrigation water prices to restrain demand, encourage the improvement of irrigation technology, return farmland to forests, and so on effectively promoted water conservation. However, a long-term plan is still required in order to completely improve the agricultural water stress in the upstream.

\subsection{Combined Result of Groundwater Changes from Agricultural Water Consumption and Water Supply}

As shown in Figure 4, the annual average spatial and time series of AWC, WS, and GWC are described to indicate the relationship between AWC and WS, and the influence on GWC. From Figure $4 \mathrm{a}$, it is found that annual average AWC at the $1^{\circ} \times 1^{\circ}$ grid ranged from about 2-320 $\mathrm{mm}$, and the spatial distribution of AWC gradually decreased from southwest to northeast in the period. In fact, the spatial distribution of AWC was closely related to WS. From Figure 4b, it is clearly found that the water endowments in the southwest corner were the best over the region because the area was a place with the most annual water supply. Also, the annual average WS in some parts of the area even exceeded $300 \mathrm{~mm}$. The spatial distribution of WS also gradually decreased from southwest to northeast. The distribution was close to the distribution of surface water. High WS and high AWC directly led to no significant increase in groundwater, as shown in Figure 4c. In contrast, not much WS with little AWC contributed to the significant increase in groundwater in the north of the TRB. However, it is still too early to draw the conclusion that the agricultural expansion has adapted to climatic risks to maintain its sustainable development in the TRB. Switching to the monthly average perspective, some new results have emerged in Figure $4 \mathrm{~d}$. The figure describes the monthly average change trends of AWC, WS, and GWC at the $1^{\circ} \times 1^{\circ}$ grid. In general, water supply could hardly meet the needs of agricultural water supply in summer, resulting in the loss of groundwater in the period. The reason why the annual average groundwater change had remained stable for many years rather than dropped is the constant supplement of snow water and rainfall in the two winter and spring seasons. It is found that groundwater was not lost (increasing) immediately in the season, but lagged by a season. For groundwater losses, the magnitude and frequency of groundwater declines after the year 2009 were more serious than before. In particular, for the two consecutive years of 2008 and 2009 , the serious shortage of water supply had directly led to a serious groundwater drop by nearly $20 \mathrm{~mm}$ from the end of 2009 to early 2010. Fortunately, the following WS, which is far larger than the normal average, made up for the deficiencies in the previous period. Another interesting phenomenon is that there was a certain degree of positive correlation between AWC and WS in the summer. In other words, the increase in the WS contributed to the growth of AWC, which indicated that agricultural production was dependent on the amount of WS in summer.

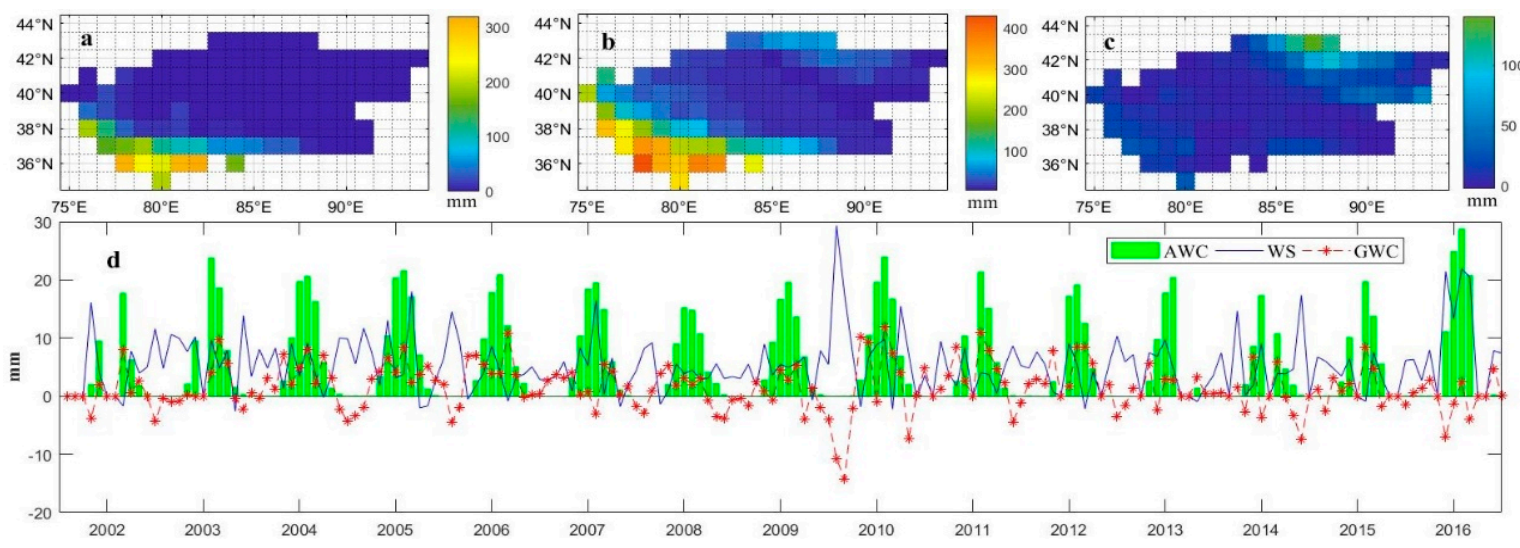

Figure 4. The annual average spatial distribution of agricultural water consumption (AWC), water supply (WS), and groundwater change (GWC) during 2002-2016. ((a-c) are spatial distributions of the annual AWC, WS, and GWC, respectively; (d) is the monthly average change trends of AWC, WS, and GWC at the $1^{\circ} \times 1^{\circ}$ grid over the region). 
Based on the above, it is known that all of them had significant seasonal variations of the cycle. So, for further understanding about the seasonal patterns of WS, GWC, and AWC, more details are provided in Figure 5. As shown in Figure $5 \mathrm{a}-\mathrm{d}$, it is found that the largest amount of WS was in summer and winter, and the least was in autumn. Also, WS was the most widely distributed in the summer, and the least widely distributed in the autumn. In the view of geographical distribution, WS was mainly distributed at the foot of the three mountains: the Tian Shan in the north, Kunlun in the south, and Pamir in the west. The highest WS was located in the southwest corner of the TRB, which was between the Kunlun and Pamir mountains. From the boxplot of the seasonal distribution of WS, it was found that the average values at the $1^{\circ} \times 1^{\circ}$ grid fluctuated around $20 \mathrm{~mm}$ in the period. Among them, the performance of WS in summer was the most stable. In winter, rich snow ensured WS. However, autumn was the driest season in the TRB. From the Figure 5e-h, areas where groundwater changed were similar to areas where water resources were supplied. So, GWC has mainly distributed into two areas: the foot of the Tian Shan, and the southwest corner of the TRB. However, the performances of GWC in these two areas were quite different. The GWC at the foot of Tian Shan showed an increasing trend, while between Kunlun and Pamir mountains it showed the opposite trend; especially, groundwater loss was as high as around $60 \mathrm{~mm}$ in winter. Given the seasonal average values at the $1^{\circ} \times 1^{\circ}$ grid, the maximum value never exceeded $20 \mathrm{~mm}$, but its minimum value was less than $0 \mathrm{~mm}$ in each season. The groundwater losses were caused by the mismatch between WS and AWC. A large amount of water consumed by crops in the summer was the key cause of groundwater losses, which far exceeded WS, and even reached up to $200 \mathrm{~mm}$ in some parts of the area (Figure 5i-1). From the boxplot of the seasonal distribution, differences in AWC in different seasons were obvious. The average value at the $1^{\circ} \times 1^{\circ}$ grid in summer was almost $60 \mathrm{~mm}$, but ones in spring and autumn were less $20 \mathrm{~mm}$.
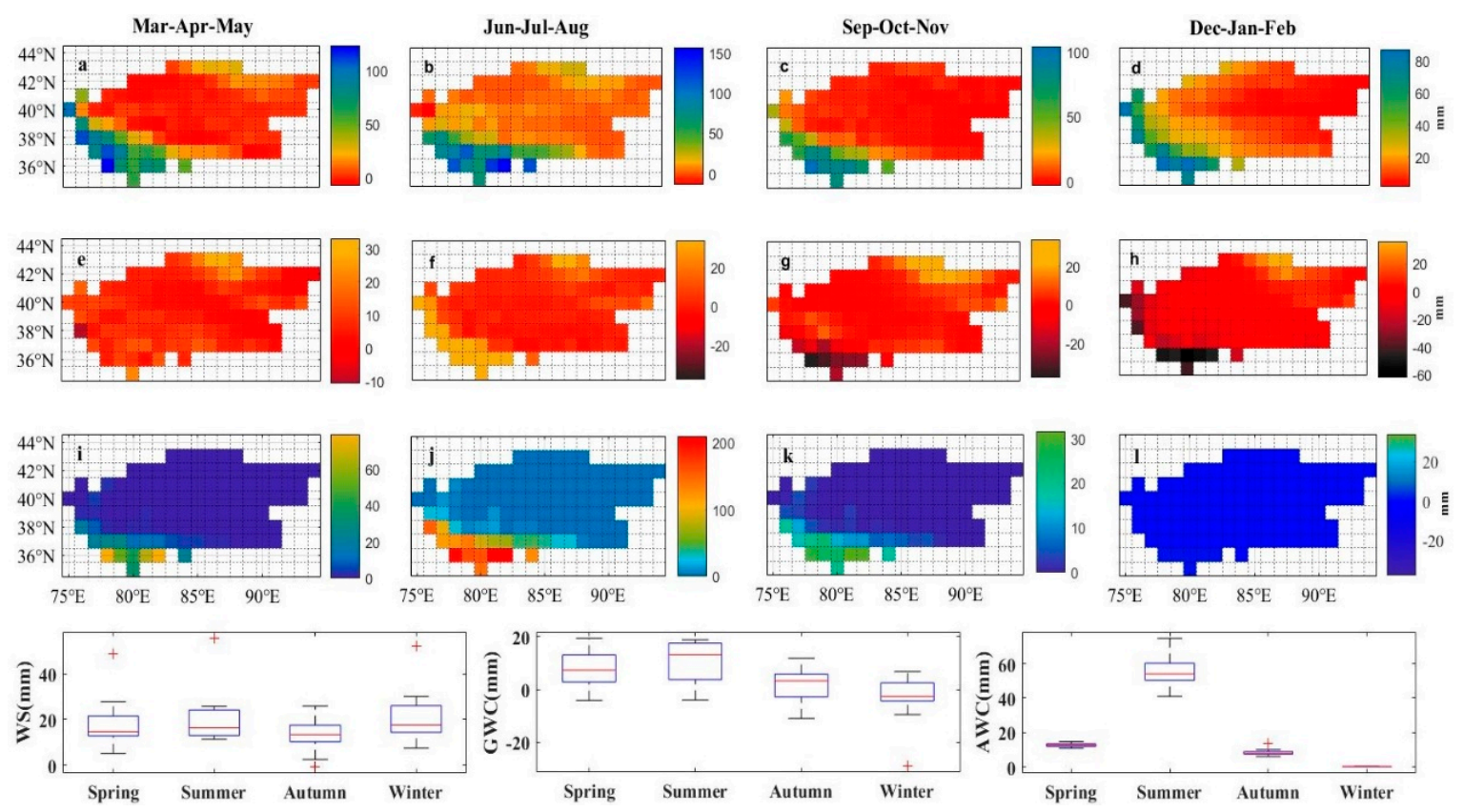

Figure 5. The seasonal patterns of WS, GWC, and AWC during 2002-2016. ((a-d) are spring, summer, autumn, and winter WS patterns, respectively; (e-h) are spring, summer, autumn, and winter GWC patterns, respectively; (i-1) are spring, summer, autumn and winter AWC patterns, respectively; the last three figures are boxplots of the seasonal distribution of WS, GWC, and AWC at the $1^{\circ} \times 1^{\circ}$ grid over the region, respectively).

Based on above, excess water resources consumed by the large-scale agriculture around the three Source Rivers should be responsible for seasonal groundwater loss and local water shortage. In spite of 
increasing water resources under climatic variability, they still fail to meet the agricultural need. Also, groundwater level decrease directly leads to insufficient water supply to vegetation, which results in natural aquatic and oasis ecosystem shrinkage in the process of agricultural expansion [53]. Besides that, water shortage in upstream inevitably leads to inadequate water delivery to the downstream, while delivered water is crucial for the fragile ecological environment downstream. A sufficient water supply can ensure underground water quality and quantity improvement, vegetation area expansion, and the restoration of ecological communities [54,55]. Apparently, agricultural expansion upstream also leads to water shortage downstream. So, it is an unwise decision to rely on an increase in water supplies due to climatic variability to achieve the expansion of food production. If the climate pattern is switching, as it did in the period of 2008-2009, it will cause catastrophic consequences for the arid TRB, such as a rapid drop in groundwater level, break-off discharge in the Tarim River, and a water use crisis. In short, from the experience of this period, agricultural development in the TRB was not sustainable under climatic risks.

Based on the above analysis, we believe that basin management should focus on two issues: water saving and water use allocation. First, effective irrigation and rainwater utilization are two important ways to control AWC to ensure water resources saving. Then, the spatial and temporal water allocation optimization aims to rational water use and ecological environment recovery.

Limited by a spatial resolution of $1^{\circ} \times 1^{\circ}$, water consumption of ecological vegetation and crop are hardly distinguished. So, the results of AWC and AWSI are exaggerated in the paper. Also, natural evaporation includes part of AWC, because water is directly evaporated in the process of irrigation, which is not accounted for AWC. Therefore, the results of AWC and AWSI are not particularly accurate estimates, but do not affect GWC. More importantly, they still fully reflect the problems that we want to analyze in the paper.

\section{Conclusions}

For arid areas, the impact of climatic risk is more significant. How to properly respond to the water resources change caused by climatic variability is the key to maintaining sustainable development. The decision-making of sustainable development in the basin is based on how to effectively evaluate the current relationship between climatic risks and human production activities. Agriculture is usually the largest water-consuming sector of a river basin, so its water use strategy under climatic risks is related to the sustainable development of water resources in the entire region. The paper, taking the TRB as an example, aims to examine the sustainability of agricultural water use in the period of increasing water resources caused by climatic variability from the evidence of groundwater change. In the context of climatic variability, more water resources were supplied from increased precipitation and snowmelt in the headstreams in the TRB. However, the change failed to be transferred into ecological environmental improvement due to the agricultural expansion.

From results, it is known that large-scale agricultural production was mostly distributed around the three Source Rivers with the richest water resources in the TRB. Based on AWSI, the relation between AWC and WS was established to describe regional water stress. These results indicated that local severe water stress caused by a large amount of AWC had led to two serious problems: regional water shortage and seasonal groundwater loss. In view of the time series of the AWSI, it showed a declining trend in the mid-late period, which indicated a gradual alleviation of regional water stress, but remained in a state of severe water stress.

As results of the annual average spatial consumption of AWC, WS, and GWC, it is found that the annual average AWC at the $1^{\circ} \times 1^{\circ}$ grid ranged within 2-320 mm, and the spatial distribution of AWC gradually decreased from southwest to northeast in the period, which was closely related to WS. Also, the annual average groundwater did not show a significant decrease. However, in the view of monthly change, groundwater levels showed seasonal fluctuations, declining in the summer and autumn, and recovering in the spring and summer. It is indicated that a large mismatch between WS and AWC in the summer led to the sharp dropping of local groundwater level in the following 
two seasons. The seasonal water shortage had caused water scarcity for the whole basin, because the runoffs of Source Rivers reduced by AWC led to break-off discharge in the mainstream. So, agricultural water use management in the TRB was still far from a sustainable state.

To be more alarmed, the magnitude and frequency of groundwater declines after the year 2009 were more serious than the years before. Particularly, in the two years of 2008 and 2009, the serious shortage of water supply in the TRB directly led to an appalling drop in groundwater by nearly $20 \mathrm{~mm}$ from the end of 2009 to early 2010. If there is no change to agricultural production expansion, climatic variability, such as in 2008 and 2009, will shift from humid to arid, and impose catastrophic consequences of great water resource system vulnerability on the arid TRB.

Acknowledgments: This work was supported by Postgraduate Research \& Practice Innovation Program of Jiangsu Province [grant number KYCX17_0509], the National Social Science Foundation of China [grant number 12CGL068], and the National Natural Science Foundation of China [grant number 51409088].

Author Contributions: Data was collected and analyzed by Jun Zhang and Minghao Bai under the supervision of Shenbei Zhou. Jun Zhang and Minghao Bai contributed to the writing and editing of the manuscript. Shenbei Zhou and Min Zhao reviewed the paper.

Conflicts of Interest: The authors declare no conflict of interest.

\section{References}

1. Cao, X.; Wu, M.; Guo, X.; Zheng, Y.; Gong, Y.; Wu, N.; Wang, W. Assessing water scarcity in agricultural production system based on the generalized water resources and water footprint framework. Sci. Total Environ. 2017, 609, 587-597. [CrossRef]

2. Vörösmarty, C.J.; McIntyre, P.B.; Gessner, M.O.; Dudgeon, D.; Prusevich, A.; Green, P.; Glidden, S.; Bunn, S.E.; Sullivan, C.A.; Liermann, C.R.; et al. Global threats to human water security and river biodiversity. Nature 2010, 467, 555-561. [CrossRef] [PubMed]

3. Bakker, K. Water security: Research challenges and opportunities. Science 2012, 337, 914-915. [CrossRef] [PubMed]

4. Le Roux, B.; van der Laan, M.; Vahrmeijer, T.; Bristow, K.L.; Annandale, J.G. Establishing and testing a catchment water footprint framework to inform sustainable irrigation water use for an aquifer under stress. Sci. Total Environ. 2017, 599, 1119-1129. [CrossRef] [PubMed]

5. Postel, S. Pillar of Sand: Can the Irrigation Miracle Last? WW Norton \& Company: New York, NY, USA, 1999.

6. Li, G.; Harrison, S.P.; Bartlein, P.J.; Izumi, K.; Colin Prentice, I. Precipitation scaling with temperature in warm and cold climates: An analysis of CMIP5 simulations. Geophys. Res. Lett. 2013, 40, 4018-4024. [CrossRef]

7. Alauddin, M.; Sarker, M.A.R. Climate change and farm-level adaptation decisions and strategies in drought-prone and groundwater-depleted areas of Bangladesh: An empirical investigation. Ecol. Econ. 2014, 106, 204-213. [CrossRef]

8. Adamson, D.; Loch, A.; Schwabe, K. Adaptation responses to increasing drought frequency. Aust. J. Agric. Resour. Econ. 2017, 61, 385-403. [CrossRef]

9. Heinemann, A.B.; Ramirez-Villegas, J.; Stone, L.F.; Didonet, A.D. Climate change determined drought stress profiles in rainfed common bean production systems in Brazil. Agric. For. Meteorol. 2017, 246, 64-77. [CrossRef]

10. Dou, X. A critical review of groundwater utilization and management in China's inland water shortage areas. Water Policy 2016, 18, 1367-1383. [CrossRef]

11. Shang, H.; Wang, W.; Dai, Z.; Duan, L.; Zhao, Y.; Zhang, J. An ecology-oriented exploitation mode of groundwater resources in the northern Tianshan Mountains, China. J. Hydrol. 2016, 543, 386-394. [CrossRef]

12. Scott, C.A. Electricity for groundwater use: Constraints and opportunities for adaptive response to climate change. Environ. Res. Lett. 2013, 8, 035005. [CrossRef]

13. Ma, J.Z.; Wang, X.S.; Edmunds, W.M. The characteristics of ground-water resources and their changes under the impacts of human activity in the arid Northwest China-A case study of the Shiyang River Basin. J. Arid Environ. 2005, 61, 277-295. [CrossRef]

14. Moore, S.; Fisher, J.B. Challenges and opportunities in GRACE-based groundwater storage assessment and management: An example from Yemen. Water Resour. Manag. 2012, 26, 1425-1453. [CrossRef] 
15. World Water Assessment Programme. Water in a Changing World: The United Nations World Water Development Report 3; UNESCO World Heritage Centre: Paris, France, 2009.

16. Foster, S.S.D.; Chilton, P.J. Groundwater: The processes and global significance of aquifer degradation. Philos. Trans. R. Soc. Lond. B Biol. Sci. 2003, 358, 1957-1972. [CrossRef] [PubMed]

17. Ostrom, E. The rudiments of a theory of the origins, survival, and performance of common-property institutions. In Making the Commons Work: Theory, Practice, and Policy; Bromley, D., Ed.; Institute for Contemporary Studies: San Francisco, CA, USA, 1992; pp. 293-318.

18. Blomquist, W. Changing rules, changing games: Evidence from groundwater systems in Southern California. In Rules, Games, and Common-Pool Resource Problems; Ostrom, E., Gardner, R., Walker, J., Eds.; University of Michigan Press: Ann Arbor, MI, USA, 1994; pp. 283-300.

19. Villholth, K.G. Groundwater assessment and management: Implications and opportunities of globalization. Hydrogeol. J. 2006, 14, 330-339. [CrossRef]

20. Gemitzi, A.; Lakshmi, V. Evaluating renewable groundwater stress with GRACE data in Greece. Ground Water 2017. [CrossRef] [PubMed]

21. Landerer, F.W.; Swenson, S.C. Accuracy of scaled GRACE terrestrial water storage estimates. Water Resour. Res. 2012, 48. [CrossRef]

22. Syed, T.H.; Famiglietti, J.S.; Rodell, M.; Chen, J.; Wilson, C.R. Analysis of terrestrial water storage changes from GRACE and GLDAS. Water Resour. Res. 2008, 44. [CrossRef]

23. Yang, T.; Wang, C.; Chen, Y.; Chen, X.; Yu, Z. Climate change and water storage variability over an arid endorheic region. J. Hydrol. 2015, 529, 330-339. [CrossRef]

24. Rodell, M.; Houser, P.R.; Jambor, U.; Gottschalck, J.; Mitchell, K.; Meng, C.-J.; Arsenault, K.; Cosgrove, A.; Radakovich, J.; Bosilovich, M.; et al. The global land data assimilation system. Bull. Am. Meteorol. Soc. 2004, 85, 381-394. [CrossRef]

25. Henry, C.M.; Allen, D.M.; Huang, J. Groundwater storage variability and annual recharge using well-hydrograph and GRACE satellite data. Hydrogeol. J. 2011, 19, 741-755. [CrossRef]

26. Ouma, Y.O.; Aballa, D.O.; Marinda, D.O.; Tateishi, R.; Hahn, M. Use of GRACE time-variable data and GLDAS-LSM for estimating groundwater storage variability at small basin scales: A case study of the Nzoia River Basin. Int. J. Remote Sens. 2015, 36, 5707-5736. [CrossRef]

27. Huo, A.; Peng, J.; Chen, X.; Deng, L.; Wang, G.; Cheng, Y. Groundwater storage and depletion trends in the Loess areas of China. Environ. Earth Sci. 2016, 75, 1167. [CrossRef]

28. Xiao, M.; Koppa, A.; Mekonnen, Z.; Pagán, B.R.; Zhan, S.; Cao, Q.; Aierken, A.; Lee, H.; Lettenmaier, D.P. How much groundwater did California's Central Valley lose during the 2012-2016 drought? Geophys. Res. Lett. 2017, 44. [CrossRef]

29. Hu, K.; Awange, J.L.; Forootan, E.; Goncalves, R.M.; Fleming, K. Hydrogeological characterisation of groundwater over Brazil using remotely sensed and model products. Sci. Total Environ. 2017, 599-600, 372-386. [CrossRef] [PubMed]

30. Li, H.T.; Brunner, P.; Kinzelbach, W.; Li, W.P.; Dong, X.G. Calibration of a groundwater model using pattern information from remote sensing data. J. Hydrol. 2009, 377, 120-130. [CrossRef]

31. Perry, C. Efficient irrigation; inefficient communication; flawed recommendations. Irrig. Drain. 2007, 56, 367-378. [CrossRef]

32. Brunner, P.; Li, H.T.; Kinzelbach, W.; Li, W.P.; Dong, X.G. Extracting phreatic evaporation from remotely sensed maps of evapotranspiration. Water Resour. Res. 2008, 44. [CrossRef]

33. Hoekstra, A.; Chapagain, A.; Aldaya, M.; Mekonnen, M. The Water Footprint Assessment Manual; Routledge: Abingdon, UK, 2011.

34. Rumbaur, C.; Thevs, N.; Disse, M.; Ahlheim, M.; Brieden, A.; Cyffka, B.; Duethmann, D.; Feike, T.; Frör, O.; Gärtner, P.; et al. Sustainable management of river oases along the Tarim River (SuMaRiO) in Northwest China under conditions of climate change. Earth Syst. Dyn. 2015, 6, 83-107. [CrossRef]

35. Xu, H.; Ye, M.; Li, J. The water transfer effects on agricultural development in the lower Tarim River, Xinjiang of China. Agric. Water Manag. 2008, 95, 59-68. [CrossRef]

36. Yang, L.P. Water Resources Distribution and Utilization in Xinjiang; Xinjiang People's Publishing House: Xinjiang, China, 1981.

37. Xu, C.; Chen, Y.; Li, W.; Chen, Y. Climate change and hydrologic process response in the Tarim River Basin over the past 50 years. Chin. Sci. Bull. 2006, 51, 25-36. [CrossRef] 
38. Tao, H.; Gemmer, M.; Bai, Y.; Su, B.; Mao, W. Trends of streamflow in the Tarim River Basin during the past 50years: Human impact or climate change? J. Hydrol. 2011, 400, 1-9. [CrossRef]

39. Huang, J.; Tao, H.; Fischer, T.; Wang, X. Simulated and projected climate extremes in the Tarim River Basin using the regional climate model CCLM. Stoch. Environ. Res. Risk Assess. 2015, 29, 2061-2071. [CrossRef]

40. Bolch, T.; Kulkarni, A.; Kääb, A.; Huggel, C.; Paul, F.; Cogley, J.G.; Frey, H.; Kargel, J.S.; Fujita, K.; Scheel, M.; et al. The state and fate of Himalayan glaciers. Science 2012, 336, 310-314. [CrossRef] [PubMed]

41. Shangguan, D.; Liu, S.; Ding, Y.; Ding, L.; Xu, J.; Jing, L. Glacier changes during the last forty years in the Tarim Interior River basin, northwest China. Prog. Nat. Sci. 2009, 19, 727-732. [CrossRef]

42. Osmonov, A.; Bolch, T.; Xi, C.; Kurban, A.; Guo, W. Glacier characteristics and changes in the Sary-Jaz River Basin (Central Tien Shan, Kyrgyzstan)-1990-2010. Remote Sens. Lett. 2013, 4, 725-734. [CrossRef]

43. Pieczonka, T.; Bolch, T. Region-wide glacier mass budgets and area changes for the Central Tien Shan between 1975 and 1999 using Hexagon KH-9 imagery. Glob. Planet. Chang. 2015, 128, 1-13. [CrossRef]

44. Krysanova, V.; Wortmann, M.; Bolch, T.; Merz, B.; Duethmann, D.; Walter, J.; Huang, S.; Tong, J.; Buda, S.; Kundzewicz, Z.W. Analysis of current trends in climate parameters, river discharge and glaciers in the Aksu River basin (Central Asia). Hydrol. Sci. J. 2015, 60, 566-590. [CrossRef]

45. Forootan, E.; Safari, A.; Mostafaie, A.; Schumacher, M.; Delavar, M.; Awange, J.L. Large-scale total water storage and water flux changes over the arid and semiarid parts of the Middle East from GRACE and reanalysis products. Surv. Geophys. 2017, 38, 591-615. [CrossRef]

46. Raskin, P.; Gleick, P.; Kirshen, P.; Pontius, G.; Strzepek, K. Water Futures: Assessment of Long-Range Patterns and Prospects; Stockholm Environment Institute: Stockholm, Sweden, 1997.

47. Swenson, S.C. GRACE Monthly Land Water Mass Grids NETCDF Release 5.0; Version 5.0; PO.DAAC: Pasadena, CA, USA, 2012.

48. Swenson, S.C.; Wahr, J. Post-processing removal of correlated errors in GRACE data. Geophys. Res. Lett. 2006, 33. [CrossRef]

49. Rodell, M.; Beaudoing, H.K. NASA/GSFC/HSL, GLDAS Noah Land Surface Model L4 Monthly $1.0 \times 1.0$ Degree V2.1; Goddard Earth Sciences Data and Information Services Center (GES DISC): Greenbelt, MD, USA, 2016.

50. Wang, J.; Liu, X.; Gong, W.; Zhou, S.; Mao, W.; Gao, Q.; Shen, Y.; Wang, S. Streamflow variations and flow-break causes of four source rivers and mainstream of Tarim River, Xinjiang in 2008. J. Glaciol. Geocryol. 2010, 32, 593-601.

51. Chen, Y.; Ye, Z.; Mao, X.; Zhang, X.; Luo, J. Dried-up trend of Tarim River and the countermeasures for mitigation. Arid Land Geogr. 2009, 32, 813-820.

52. Hao, Y.; Kasim, T.; Yang, J.; Turhan, A.; Ghopur, A. Study on the influence of the downstream runoff change of the Tarim River on desertification. Res. Soil Water Conserv. 2013, 20, 145.

53. Fanhao, M.; Jiapaer, G.; Anming, B.; Hui, G.; Min, L.; Tie, L. Analysis on the relationship between agriculture water consumption of four source rivers and the change of ecosystem structure of the mainstream in Tarim River Basin in recent 50 years. J. Nat. Resour. 2016, 31, 1832-1843.

54. Deng, M.; Zhou, H.; Xu, H.; Ling, H.; Zhang, P. Research on the ecological operation in the lower reaches of Tarim River based on water conveyance. Sci. Sin. Technol. 2016, 46, 864-876.

55. Li, W.H.; Chen, Y.J.; Chen, Y.P.; Huang, X. Effects of ecological stream water transfusion on groundwater level and quality in the lower reaches of the Tarim river. Resour. Sci. 2006, 28, 157-163.

(C) 2018 by the authors. Licensee MDPI, Basel, Switzerland. This article is an open access article distributed under the terms and conditions of the Creative Commons Attribution (CC BY) license (http:/ / creativecommons.org/licenses/by/4.0/). 